\title{
STABILITY ANALYSIS OF ORTHOTROPIC REINFORCE CONCRETE SHEAR WALL
}

\author{
J. C. Ezeh ${ }^{1}$, Owus M. Ibearugbulem ${ }^{2}$, Uchechi T. Echehum ${ }^{3}$ \\ ${ }^{1}$ Associate professor, ${ }^{2}$ Senior Lecturer, ${ }^{3}$ Postgraduate student, Civil Engineering Department, Federal University of \\ Technology Owerri, Imo state, Nigeria
}

\begin{abstract}
This paper studied the stability analysis of orthotropic reinforced concrete shear wall panel with all edges simply supported by the application of Ritz method. The study was carried out through a theoretical formulation based on applying polynomial series deflection function in Ritz method. The polynomial series as used here was truncated at the fifth term, which satisfied all the boundary conditions of the panel and resulted to a particular shape function for simply supported edges (SSSS) panel. Orthotropic parameter ratios of flexural plate rigidities in $x, y$ and $x$-y directions to flexural plate rigidity in $x$ direction are 1.0, 0.5 and 0.1 respectively. The critical buckling load obtained herein based on this orthotropy for different aspect ratios were compared with those obtained by Iyengar. This comparison showed that the maximum percentage difference recorded is $0.01382 \%$. For aspect ratios of 0.5 and 1.0 , the critical buckling loads are $42.74 \mathrm{Dx} / \mathrm{b} 2$ and $16.799 \mathrm{Dx} / \mathrm{b} 2$.
\end{abstract}

Keywords: Critical buckling load, in-plane load, shape function, boundary conditions, total potential energy functional, orthotropic parameter, reinforced concrete.

$* * *$

\section{INTRODUCTION}

It has been discovered that in the past, orthotropic shear wall panel problems have been treated by the use of either trigonometric series as the shape function or Fourier series as the shape function in representing deformed shape of the shear wall panels. Many literatures solved the problems with different approach such as numerical, energy and equilibrium approaches. . However, [1] tried solving plate problems using single Fourier series because of the slow convergence of double Fourier series used by [2]. [3] also used Fourier series in their work. [4] and [5] solved a problem of buckling of axially compressed SSSS thin isotropic rectangular plate using polynomial series deflection function in Ritz method. This paper used Polynomial series shape function in Ritz method to analyze the critical buckling load of orthotropic shear wall panel with all edges simply supported subjected to in-plane loading along one axis ( $\mathrm{x}$-axis) of the principal plane.

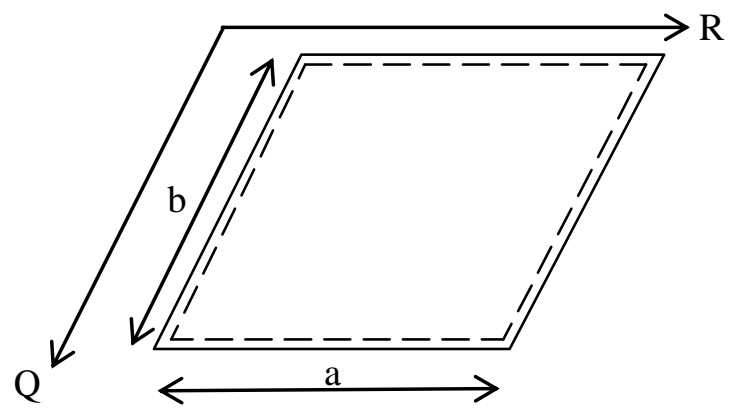

Fig-1: Schematic representation of simply supported edges panel.

\section{TOTAL POTENTIAL ENERGY FUNCTIONAL FOR REINFORCED CONCRETE SHEAR WALL PANEL.}

[6] derived the total potential energy functional for orthotropic reinforced concrete shear wall panel subjected to in-plane load in $\mathrm{x}$ - direction as follows: 


$$
\begin{aligned}
\prod_{\mathrm{x}}=\frac{1}{2 \mathrm{~b}^{2}} \int_{A}\left\{\frac{D_{x}}{\mathrm{p}^{3}}(\right. & \left.\frac{\partial^{2} w}{\partial R^{2}}\right)^{2}+\frac{\mathrm{H}}{\mathrm{p}}\left(\frac{\partial^{2} w}{\partial R^{2} \partial Q^{2}}\right)^{2} \\
& \left.+\mathrm{p} D_{y}\left(\frac{\partial^{2} w}{\partial Q^{2}}\right)^{2}\right\} \partial R \partial Q \\
& -\frac{\mathrm{N}_{(\mathrm{x})}}{2 \mathrm{p}} \int_{A}\left(\frac{\partial \mathrm{w}}{\partial \mathrm{R}}\right)^{2} \partial R \partial Q
\end{aligned}
$$

Where $\mathrm{N}_{\mathrm{x}}$ is the in-plane load in $\mathrm{x}$ - direction

$\mathrm{W}$ is the shape function;

$$
\text { Aspect ratio, } \mathrm{P}=\frac{\mathrm{a}}{\mathrm{b}}
$$

Orthotropic parameters are:

$\emptyset_{1}=\frac{D_{x}}{D_{x}} ; \emptyset_{2}=\frac{H}{D_{x}} ; \emptyset_{3}=\frac{D_{y}}{D_{x}}$

$D_{\mathrm{x}}$ Is the flexural rigidity in $\mathrm{x}$ - direction

$D_{\mathrm{y}}$ Is the flexural rigidity in $\mathrm{y}$ - direction

$D_{\mathrm{xy}}$ Is the twisting flexural rigidity in $\mathrm{x}-\mathrm{y}$ plane

$\mathrm{H}=\mathrm{VxDy}+2 \mathrm{Dxy}=\mathrm{VyDx}+2 \mathrm{Dxy}$

$\prod_{\mathrm{x}}$ is the total potential energy functional along, $\mathrm{R}=$ $\frac{\mathrm{x}}{\mathrm{a}}, \mathrm{Q}=\frac{\mathrm{x}}{\mathrm{b}}$,

$0 \leq \mathrm{R} \leq 1 ; 0 \leq \mathrm{Q} \leq 1$. ( $R$ and $\mathrm{Q}$ are dimensionless quantities).

\section{SHAPE FUNCTION FROM POLYNOMIAL}

\section{SERIES.}

Ibearugbulem (2012) gave the shape function for rectangular panels which was truncated at $\mathrm{m}=\mathrm{n}=4$ as:

$$
W=\sum_{m=o}^{4} \sum_{n=o}^{4} J_{m} K_{n} R^{m} Q^{n}
$$

On expansion, equation (2) becomes:

$$
\begin{array}{cc}
\mathrm{W}=\left(J_{0}+J_{1} \mathrm{R}+J_{2} R^{2}+J_{3} R^{3}+J_{4} R^{4}\right) & \left(K_{0}+K_{1} Q+\right. \\
\left.K_{2} Q^{2}+K_{3} Q^{3}+K_{4} Q^{4}\right) & (3)
\end{array}
$$

The boundary condition for simply supported edges shear wall panel is:

$$
\begin{aligned}
& \mathrm{W}(\mathrm{R}=0, \mathrm{Q})=0 \quad \mathrm{~W}(\mathrm{R}=1, \mathrm{Q})=0 \\
& \mathrm{~W} 11 \mathrm{R}(\mathrm{R}=0, \mathrm{Q})=0 \mathrm{~W} 11 \mathrm{R}(\mathrm{R}=1, \mathrm{Q})=0 \\
& \mathrm{~W}(\mathrm{R}, \mathrm{Q}=0)=0 \quad \mathrm{~W}(\mathrm{R}, \mathrm{Q}=1)=0 \\
& \mathrm{~W} 11 \mathrm{Q}(\mathrm{R}, \mathrm{Q}=0)=0 \quad \mathrm{~W} 11 \mathrm{Q}(\mathrm{R}, \mathrm{Q}=1)=0
\end{aligned}
$$

Substitute these boundary conditions into equation (3) gave

$$
\mathrm{W}=\mathrm{A}[\mathrm{R}-2 \mathrm{R} 3+\mathrm{R} 4][\mathrm{Q}-2 \mathrm{Q} 3+\mathrm{Q} 4]
$$

Where $\mathrm{A}=\mathrm{J} 4 \mathrm{~K} 4$;

\section{APPLICATION OF RITZ METHOD}

Integrating the squares of second partial derivatives of equation (8) gave:

$$
\begin{gathered}
\int_{0}^{1} \int_{0}^{1}\left(\frac{\partial \mathrm{w}}{\partial \mathrm{R}}\right)^{2} \partial \mathrm{R} \partial \mathrm{Q}=\mathrm{A}^{2}(0.48571)(0.04921) \\
=0.0239 \mathrm{~A}^{2} \\
\int_{0}^{1} \int_{0}^{1}\left(\frac{\partial w}{\partial Q}\right)^{2} \partial R \partial Q=\mathrm{A}^{2}(0.04921)(0.48571) \\
=0.0239 \mathrm{~A}^{2} \\
\int_{0}^{1} \int_{0}^{1}\left(\frac{\partial^{2} w}{\partial R^{2}}\right)^{2} \partial R \partial Q=\mathrm{A}^{2}(4.80)(0.04921) \\
=0.23621 \mathrm{~A}^{2} \\
\int_{0}^{1} \int_{0}^{1}\left(\frac{\partial^{2} w}{\partial Q^{2}}\right)^{2} \partial R \partial Q=\mathrm{A}^{2}(0.04921)(4.80) \\
=0.023621 \mathrm{~A}^{2} \\
\int_{0}^{1} \int_{0}^{1}\left(\frac{\partial^{2} w}{\partial R \partial Q}\right)^{2} \partial R \partial Q=\mathrm{A}^{2}(0.48571)(0.048571) \\
=0.023591 \mathrm{~A}^{2}
\end{gathered}
$$

Substituting equations (9) to (13) into equations (1) gave:

$$
\begin{gathered}
\Pi_{x}=\frac{A^{2}}{2 b^{2}}\left[\left(\frac{0.23621 D_{x}}{P^{3}}\right)+\left(\frac{0.47182 H}{P}\right)+\left(0.23621 P_{y}\right)\right] \\
-\left[\frac{A^{2} N_{x}}{2 p}(0.2391)\right]
\end{gathered}
$$

That is

$$
\begin{gathered}
\Pi_{\mathrm{x}}=\frac{\mathrm{A}^{2} \mathrm{D}_{\mathrm{x}}}{2 \mathrm{~b}^{2}}\left[\left(\frac{0.23621 \emptyset_{1}}{\mathrm{P}^{3}}\right)+\left(\frac{0.47182 \emptyset_{2}}{\mathrm{P}}\right)\right. \\
\left.+\left(0.23621 \mathrm{P} \emptyset_{3}\right)\right] \\
-\left[\frac{\mathrm{A}^{2} \mathrm{~N}_{\mathrm{x}}}{2 \mathrm{p}}(0.2391)\right]
\end{gathered}
$$

Minimizing equation (15) gave:

$$
\begin{aligned}
& \frac{\partial \Pi_{x}}{\partial A}=\frac{\mathrm{A} D_{x}}{P^{3} b^{2}}\left[\left(0.23621 \emptyset_{1}\right)+\left(0.47182 P^{2} \emptyset_{2}\right)\right. \\
& \left.+\left(0.23621 P^{4} \emptyset_{3}\right)\right] \\
& -\frac{\left[0.0239 \mathrm{AN}_{x}\right]}{P}=0
\end{aligned}
$$


Orthotropic parameters used here are:

$$
\emptyset_{1}=1.0 ; \emptyset_{2}=0.1 ; \emptyset_{3}=0.5
$$

Making $\mathrm{N}_{\mathrm{x}}$ the subject of equation (16) gave:

$$
\begin{array}{r}
N_{x}=\frac{D_{x}}{b^{2}}\left(\frac{1.0014 \emptyset_{1}}{P^{2}}+2.00022 \emptyset_{2}\right. \\
\left.+1.0014 \emptyset_{3} P^{2}\right) \pi^{2}
\end{array}
$$

Substituting equation (17), that is orthotropic parameters $\left(\varnothing_{1}\right.$, $\emptyset_{2}$ and $\emptyset_{3}$ ) in equation (18), gave:

$N_{x}=\frac{D_{x}}{b^{2}} Z$

Where $Z=\pi^{2}\left(\frac{1.0014}{P^{2}}+0.200022\right.$

$$
\left.+0.25007 P^{2}\right)
$$

\section{RESULT AND DISCUSSION}

Result of orthotropic shear wall panel with all four edges simply supported is given by the general solution obtained in this research work as follows;

$N_{x}$

$=\frac{\pi^{2} D_{x}}{b^{2}}\left(\frac{1.0014}{P^{2}}+0.200022\right.$

$\left.+0.5007 P^{2}\right)$ present study's critical load equation

$$
\begin{aligned}
& N_{x} \\
& =\frac{\pi^{2} D_{x}}{b^{2}}\left(\frac{1.0}{P^{2}}+0.20\right. \\
& \left.+0.50 P^{2}\right) \quad \text { Iyengar's critical load equation }
\end{aligned}
$$

Substituting the aspect ratios in the range of $0.1 \leq \mathrm{P} \leq 2.0$ into equations (21) and (22) gave the numerical values presented on table 1 for the stability coefficient (Z)

Table 1: Buckling coefficient ( $\mathrm{Z}$ ) for panel with all edges simply support conditions of aspect ratios $\mathrm{a} / \mathrm{b}$ from present study.

\begin{tabular}{|c|c|c|c|}
\hline $\begin{array}{c}\text { Aspec } \\
\text { tratio } \\
\text { P. }\end{array}$ & Present study & $\begin{array}{c}\text { Iyenger's } \\
\text { study } \\
(1988)\end{array}$ & $\begin{array}{c}\text { Parcentage } \\
\text { difference (\%) }\end{array}$ \\
\hline 0.1 & 990.3657398 & 988.983709 & 0.013820308 \\
\hline 0.2 & 249.2573526 & 248.911423 & 0.003459296 \\
\hline 0.3 & 112.2346903 & 112.0803242 & 0.001543661 \\
\hline
\end{tabular}

\begin{tabular}{|r|r|r|r|}
\hline 0.4 & 64.5361983 & 64.44851674 & 0.000876816 \\
\hline 0.5 & 42.74325313 & 42.68603903 & 0.000572141 \\
\hline 0.6 & 31.20710352 & 31.16601745 & 0.000410861 \\
\hline 0.7 & 24.56582503 & 24.53402376 & 0.000318013 \\
\hline 0.8 & 20.57967964 & 20.55345117 & 0.000262285 \\
\hline 0.9 & 18.17867923 & 18.15580745 & 0.000228718 \\
\hline 1.0 & 16.79927078 & 16.77832748 & 0.000209433 \\
\hline 1.1 & 16.12172546 & 16.1017294 & 0.000199961 \\
\hline 1.2 & 15.95368914 & 15.93392799 & 0.000197611 \\
\hline 1.3 & 16.17380808 & 16.1537392 & 0.000200689 \\
\hline 1.4 & 16.70245359 & 16.68164564 & 0.000208079 \\
\hline 1.5 & 17.48561952 & 17.46371668 & 0.000219028 \\
\hline 1.6 & 18.48562964 & 18.46232873 & 0.000233009 \\
\hline 1.7 & 19.67555173 & 19.65058727 & 0.000249645 \\
\hline 1.8 & 21.03572025 & 21.00885421 & 0.00026866 \\
\hline 1.9 & 22.55150443 & 22.52251926 & 0.000289852 \\
\hline 2.0 & 24.21183717 & 24.18053078 & 0.000313064 \\
\hline
\end{tabular}

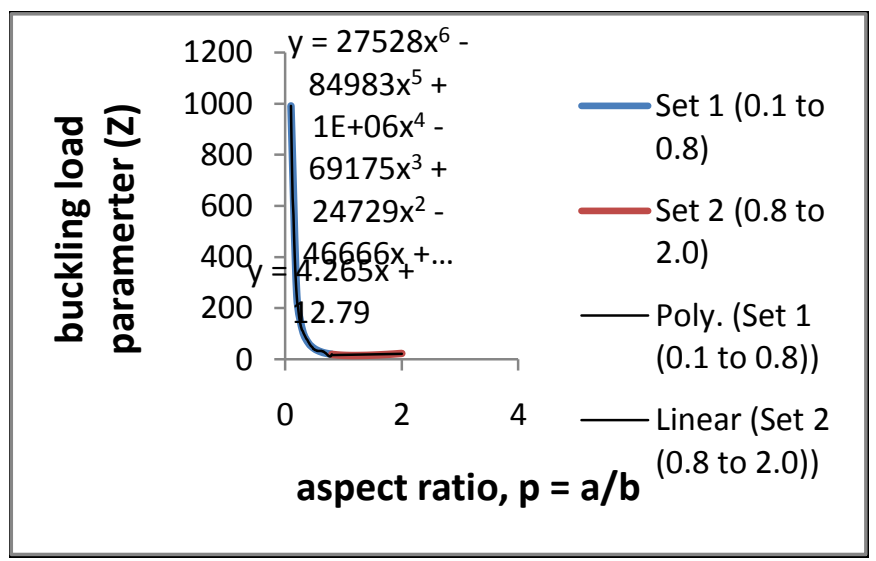

Fig 1: Graph of Stability coefficient (Z) for various aspect ratios $\mathrm{a} / \mathrm{b}$ from present study

The stability coefficient values of $\mathrm{Z}$ obtained from the present study are slightly higher than those obtained from reference work (Iyenger) as shown on table 1. Therefore, by observing this table 1 very closely, it was concluded that the closeness of the two solutions (that is, present work and Iyenger's work) improved as the aspect ratio increases from 0.1 to 2 (percentage difference column on the table 1). This shows that the present research study gives solution that is very close to those gotten from previous research work. For aspect ratios of 0.8 the present solution is approximately the same with previous study, when the values given in table 1 are taken to two decimal places only. Thus, this reveals that the present 
shape function is absolutely very close to the exact shape function. The maximum percentage difference obtained herein is $0.013820308 \%$ which occurred at aspect ratio of 0.1 , while the average percentage difference between the present study and the reference study as shown on table 1 is $0.001204057 \%$. Furthermore, the graph gave a polynomial equation representing the two curves (set 1 and set 2). Set 1 is the stability coefficient parameter $(\mathrm{Z})$ curve within the aspect ratio range of 0.1 to 0.8 . Set 21 is the stability coefficient parameter $(\mathrm{Z})$ curve within the aspect ratio range of 0.8 to 2.0.These curve equations are respectively for set 1 and set 2 :

$$
\begin{gathered}
y=275284 x 6-849835 x 5+1 E+06 x 4-691756 x 3+247290 x 2 \\
-46666 x+3777.5 ; \\
y=4.2659 x+12.793
\end{gathered}
$$

These equations can be used to calculate the stability coefficient (in this case ' $y$ ') of the panel when the aspect ratio (in this case ' $x$ ') is known.

\section{REFERENCES}

[1]. Levy, M., (1899), Memoire sur la theorie des plaques elastiques planes Journal de Mathematiques Pures et Appliquees, 3, pp 219.

[2]. Navier, C.L.M.N., (1823), Bulletin des Science de la Societe Philomarhique de paris.

[3]. Iyengar, N.G. (1988). Structrual stability of Columns and plates. Chichester: Ellis Horwood.

[4]. Ibearugbulem, O.M.; Osadebe, N.N.; Ezeh, J. C.; Owuka, D. O. (2012). Buckling Analysis of axially compressed Simply Supported Edges Thin Rectangular Pate. International Journal of Civil and Structural Engineering, Vol 2, N0 2, pp 667 671, ISSN 0976 - 4399.

[5]. Ibearugbulem, O. M. (2012). Application of a Direct Variational Principle in Elastic Stability Analysis of Thin Rectangular Flat Plates. Ph. D Thesis Submitted to the School of Postgraduate Studies, Federal University of Technology, Owerri.

[6]. Echehum, U. T. (2014). Stability analysis of orthotropic reinforce concrete shear wall. M. Eng Thesis Submitted to the School of Postgraduate Studies, Federal University of Technology, Owerri. 